\title{
Death Diagnosis Assessment Test Code
}

National Cancer Institute

\section{Source}

National Cancer Institute. Death Diagnosis Assessment Test Code. NCI Thesaurus. Code C117544.

A character or string that represents the short code name of the death diagnosis assessment. 